\title{
Quantitation of Polydeoxyribonucletides (PDRNs) in Human Placental Extract by Fluorescence Spectroscopy Using Ethidium Bromide
}

\author{
Piyali Datta Chakraborty ${ }^{*}$, Sutapa Goswami1, Sudipta Bera1, Indranil Mukhopadhyay² \\ ${ }^{1}$ Department of Research and Development, Albert David Ltd., Kolkata, India \\ ${ }^{2}$ Department of Human Genetics, Indian Statistical Institute, Kolkata, India \\ Email: ${ }^{*}$ piyali@adlindia.in, ${ }^{*}$ p_dattach@rediffmail.com
}

Received 19 June 2014; revised 7 August 2014; accepted 23 August 2014

Copyright (C) 2014 by authors and Scientific Research Publishing Inc.

This work is licensed under the Creative Commons Attribution International License (CC BY). http://creativecommons.org/licenses/by/4.0/

(c) (i) Open Access

\begin{abstract}
Characterization of an aqueous extract of human placenta, used as a licensed drug for wound healing, leads to the identification of several bioactive components including polydeoxyribonucleotides (PDRNs). PDRNs are mixture of DNA fragments of different molecular weight. A spectrofluorimetric method of quantitation of PDRNs in the aqueous extract of human placenta by using ethidium bromide (EtBr) has been described here. It has been demonstrated by thin layer chromatography (TLC) followed by reversed phase HPLC that EtBr binds specifically with the PDRN fraction of the multi-component extract. The binding specificity of EtBr has been verified by the analysis of emission spectra of the extract. A concentration of $0.29 \mu \mathrm{g} / \mathrm{ml} \mathrm{EtBr}$ exhibits a linear range of standard CT-DNA from $0.5-5 \mu \mathrm{g} / \mathrm{ml}$ of buffer $\left(R^{2}=0.992\right)$. The same concentration of EtBr shows a linear range of measurements of placenta extract from $5-35 \mu \mathrm{l} / \mathrm{ml}$ of buffer $\left(R^{2}=0.976\right)$. The points of the curve were the average of three sets where maximum variation observed was $\pm 3 \%$. PDRN content of the extract has been estimated based on the resultant fluorescence emission (after background correction) with respect to the standard calibration curve of calf thymus DNA (CT-DNA). Estimation of PDRN in a large number of batches of placenta extract $(n=100)$ has been done. The statistical analysis of the estimation was found to be significant and the lower and upper levels of PDRN were 158.30 and $239.03 \mu \mathrm{g} / \mathrm{ml}$ of the extract respectively. This easy-to-use method of estimation of PDRN in multi-component biological extract is reported for the first time. This will help in quantitation of PDRNs for other biological extracts.
\end{abstract}

\footnotetext{
*Corresponding author.
} 


\section{Keywords}

\section{Human Placental Extract, Wound Healing, PDRN, Ethidium Bromide, Fluorescence Spectroscopy}

\section{Introduction}

Aqueous extract of human placenta is used as wound healer from distant past and it contains several bioactive therapeutic molecules. The wound healing potency and anti-inflammatory action of the extract is clinically well established. The extract is successfully used in chronic non-healing wounds including post-surgical dressings, high degree burn injuries, etc. [1] [2]. The healing characteristics of placental extract are mainly attributed to the numerous biologically active substances like peptides, growth factors, glycosaminoglycans, polydeoxyribonucleotides (PDRNs) and several small molecules which are indispensable to foetal growth and protects the foetus against any pathophysiological condition [3] [4]. Its significant role in the various stages of healing has also been observed by its effective stimulation of collagen synthesis during regeneration and epithelialisation [5].

Earlier it has been demonstrated that the aqueous extract of human placenta contains a significant amount of PDRNs. The quantification of PDRNs has been done by HPLC after fractionating the component from the extract [3]. PDRN is the active fraction used as tissue repair-stimulating agent and is extracted from the different biological source in the western world [6]. The fraction is obtained by an extractive process with a high temperature in order to purify the substance. This compound holds a mixture of deoxyribonucleotide polymers with chain lengths ranging between 50 and 2000 base pairs, and may also represent the source of purine, pyrimidine and deoxynucleosides/deoxyribonucleotides and bases. In vitro PDRN has shown to enhance the growth rate of human fibroblasts and osteoblasts in primary cultures at therapeutic concentrations [7] [8]. Recent clinical studies have also pointed out that PDRN promotes a more rapid healing process of autologous skin graft donor sites and stimulates corneal epithelium regeneration after photorefractive keratectomy [9]. The favorable effect on cell proliferation enhancement appears to be mediated by the activation of purinergic $A_{2}$ receptor [10]. Further, PDRN has also not been studied extensively in vivo, especially in situations of diabetes-related healing deficit [11] [12].

Characterization of an aqueous extract of human placenta which is used as a licensed drug, leads to the identification of several bioactive components like NADPH [13] [14]; fibronectin type III-like peptide has been shown to stabilize trypsin activity [4] [15] and a ubiquitin-like peptide which exhibits collagenolytic activity and is probably involved in the remodelling phase of healing [16]. The extract also exhibits anti-microbial activity against commonly occurring pathological organisms [17], in vitro induction of NO by mouse peritoneal macrophages [18] along with enhancement of cell adhesion [19]. These findings emphasize the regulatory action exhibited by the placental extract. We have also reported that the aqueous extract of human placenta manufactured indigenously contains PDRNs. It has also been shown that PDRN fraction of the extract posses' inhibitory effect on the growth of a large variety of microbes like bacteria and fungi [17]. The main target of this study is to quantify PDRNs as one of the most biologically active components present in an aqueous extract of human placenta.

Ethidium Bromide (EtBr) is the most widely used fluorescent dye in nucleic acid gel electrophoresis since decades. While investigating sensitivity and dynamic range of available fluorophores, it has been found that $\mathrm{EtBr}$ permits much more sensitive fluorimetric measurements of DNA than previously thought [20]. Earlier report demonstrated a revised and accurate protocol for EtBr-based DNA quantification in solution which usefully complements the widely used indirect quantification of DNA on agarose gels [21] [22]. But there is no such method available in the literature for the quantitation of PDRNs by fluorescence spectroscopy. Here we report for the first time the quantitation of PDRNs in aqueous extract of human placenta by ethidium bromide as fluorephore. Further the consistency of the PDRNs in different batches of the extract has also been measured to check its reproducibility and subsequent statistical analysis have also been done.

\section{Materials and Methods}

\subsection{Reagents}

The drug "Placentrex", an aqueous extract of human placenta was manufactured by Albert David Ltd, Kolkata, India. Each milliliter of the drug was derived from $0.1 \mathrm{~g}$ of fresh placenta. A single batch was prepared from the 
pool of several placentae [13]. The following fine chemicals were procured as mentioned: Acrylamide, Bisacrylamide from Fluka, USA; Tris-HCl, Borate, Ethidium bromide (EtBr) of SRL, India, Calf thymus DNA (CTDNA) (Sigma); EDTA (Ethylenediaminetetraacetic acid), TEMED (Tetramethylethylenediamine), ammonium persulphate (APS) were from Merck, bromophenol blue and glycerol were from Qualigen; 1000 bp DNA marker was from Fermentus.

\subsection{Preparation of Concentrated Placental Extract}

Placental extract in $25 \mathrm{ml}$ volume as supplied, was dried in wide mouth glass beaker in vacuum desiccators over sodium hydroxide pellets at ambient temperature. The dried mass was reconstituted with $250 \mu \mathrm{l}$ of water after slowly stirring with a glass rod and collected. Recovery from the beaker was repeated twice using $25 \mu \mathrm{l}$ of water and the pooled fraction was centrifuged in $1.5 \mathrm{ml}$ eppendorff tubes at $10 \mathrm{~K} \mathrm{rpm}$ for $10 \mathrm{~min}$ in a bench top centrifuge. The yellowish liquid that was separated between the precipitate and the floating fat layer was carefully collected as far as possible. It was centrifuged again to collected clear solution for analysis in TLC and subsequent HPLC studies.

\subsection{Optical Instruments}

Fluorescence was recorded with a PerkinElmer LS-55 recording spectrofluorimeter with a $3 \mathrm{ml}$ quartz cuvette. Excitation and emission slit widths were $10 / 5 \mathrm{~nm}$. Optical absorbance were measured with a digital UV-Vis spectrophotometer (model No. UV-1601 of Shimadzu).

\subsection{Polyacrylamide Gel Electrophoresis (PAGE)}

A 15\% poly acrylamide gel was prepared by following standard protocol. The composition of the gel was $3 \mathrm{ml}$ of 30\% Acrylamide:Bisacrylamide (37.5:1), $0.6 \mathrm{ml}$ of 10× TBE, $2.4 \mathrm{ml}$ sterile water, $60 \mu \mathrm{l} 10 \%$ APS and $6 \mu \mathrm{l}$ TEMED. The wells of the gel were washed with the TBE buffer in order to flush out any remnant gel. Then the gel was inserted into the gel running system and running buffer $(0.5 \times$ TBE) was added. The wells of the gel were loaded with the samples i.e. 100 fold concentrated placenta extract (i.e. Placentrex) in different concentrations along with standard DNA marker. The electrophoresis was completed at $10 \mathrm{~mA}$ current. Sample was loaded with Etbr and the gel is visualized through UV transilluminator.

\subsection{Thin Layer Chromatography (TLC)}

TLC were done with two solvent systems: a) ethanol: ethyl acetate: water $(70: 20: 10(\mathrm{v} / \mathrm{v} / \mathrm{v}))$ and b) ethanol: methanol: ethyl acetate: water (50:30:10:10 $(\mathrm{v} / \mathrm{v} / \mathrm{v} / \mathrm{v}))$ using $10 \times 5 \mathrm{~cm}$ silica gel $60 \mathrm{~F}_{254}$ aluminium impregnated TLC sheets (Merck, Germany). Chromatograms were developed at $28^{\circ} \mathrm{C}$ and the spots were viewed under short wavelength UV irradiation at $254 \mathrm{~nm}$ and long wavelength at $366 \mathrm{~nm}$ by TLC photo documentation unit (DESAGA, Sarstedt-Grupe, Cab-UVIS, Germany). Placental extract was concentrated 50-fold under vacuum from which $5 \mu \mathrm{l}$ extract with EtBr (35 ng), $5 \mu \mathrm{l}$ of extract and only EtBr (35 ng) were applied on TLC plates. Concentration of the drug did not leave any precipitation or turbidity.

From the TLC plate the separated spots of placenta extract was eluted. The portion of the TLC plate containing the spots was carefully cut. Then the small pieces of the plates were dissolved into the $1 \mathrm{ml}$ of Na-phosphate buffer (pH 7.4) in $5 \mathrm{ml}$ glass tube for $1 \mathrm{hr}$. While the silica gel gets suspended into the buffer, the solution was centrifuged at $10 \mathrm{~K} \mathrm{rpm}$ for $10 \mathrm{~min}$. Then the supernatant was subjected to further analysis.

\subsection{Reversed-Phase (RP)-HPLC}

The eluted spots along with standard CT-DNA was also analyzed using reversed-phase $\mathrm{C}_{18}$-analytical column (4.6 mm $\times 150 \mathrm{~mm}$; $5 \mu$ particle size) of Phenomenex, equilibrated with $20 \mathrm{mM}$ Na-phosphate buffer, $\mathrm{pH}$ 7.5. All the samples were eluted isocratically with the same buffer at a flow rate of $1 \mathrm{ml} / \mathrm{min}$ and were monitored at $220 \mathrm{~nm}$ as well as $260 \mathrm{~nm}$ [3].

\section{Spectrofluorimerty}

\subsection{Preparation of CT-DNA as Standard}

CT-DNA was dissolved in distilled water to prepare the stock concentration of $0.8 \mathrm{mg} / \mathrm{ml}$. The concentration 
was confirmed by measuring absorbance of the solution using the procedure provided by the manufacturer (Sigma, USA).

\subsection{Preparation of EtBr}

EtBr $0.7 \mathrm{mg} / \mathrm{ml}$ was dissolved in distilled water. Finally, the working solution was prepared at a concentration of $0.014 \mathrm{mg} / \mathrm{ml}$. The concentration of the working solution was further verified with the molar extinction coefficient of EtBr i.e. $\varepsilon_{476}=5680 \mathrm{M}^{-1} \cdot \mathrm{cm}^{-1}$. To reach the best signal-to-noise ratios, $\mathrm{EtBr}$ was tested in different concentrations $(0.07,0.14$, and $0.29 \mu \mathrm{g} / \mathrm{ml})$ by measuring fluorescence (Ex: $270 \mathrm{~nm})$. It has been observed that at Ex: $270 \mathrm{~nm}$ and Em: 550 - $830 \mathrm{~nm}$ the EtBr $0.29 \mu \mathrm{g} / \mathrm{ml}$ has no detectable fluorescence.

\subsection{Preparation of Buffer}

A) $7.27 \mathrm{~g}$ of Tris (hydroxymethyl) aminomethane and $5.27 \mathrm{~g}$ of sodium chloride was dissolved in $1000 \mathrm{ml}$ distilled water and the $\mathrm{pH}$ was adjusted to 7.4 by $1(\mathrm{~N}) \mathrm{HCl}$.

B) $0.1 \mathrm{mM}$ EDTA was prepared in distilled water.

Working solution was prepared by mixing $250 \mu \mathrm{l}$ of solution A \& $250 \mu \mathrm{l}$ of solution B in a volumetric flask and final volume was adjusted to $250 \mathrm{ml}$ with distilled water [20].

\subsection{Procedure}

In a $3 \mathrm{ml}$ cuvette, $5 \mu \mathrm{l}$ of placenta extract was taken in $2 \mathrm{ml}$ of buffer (Tris-EDTA, $\mathrm{pH} 7.4$ ) and the fluorescence emission between 550 - $830 \mathrm{~nm}$ was measured after excitation at $270 \mathrm{~nm}$ (a). $5 \mu \mathrm{l}$ of placenta extract and $20 \mu \mathrm{l}$ of Etbr from $0.014 \mathrm{mg} / \mathrm{ml}$ of working solution (i.e. $0.29 \mu \mathrm{g} / \mathrm{ml}$ ) was taken in total volume of $2 \mathrm{ml}$ of buffer. The solution was mixed well and subjected to fluorescence analysis. Emission spectrum $(550-830 \mathrm{~nm})$ of the solution was taken after excitation at $270 \mathrm{~nm}$ (a'). The resultant spectrum was derived by subtracting (a) from (a') with the system of data handling provided by the in-built software "FL WinLab". The fluorescence intensity was measured at emission maxima (i.e. $617.0 \mathrm{~nm}$ ) of the resultant spectrum. In all the measurement background correction was done by the buffer.

\section{Results}

\subsection{Polyacrylamide Gel Electrophoresis}

50 fold concentrated placenta extract in different concentrations were run along with 1000 bp DNA marker in a polyacrylamide gel in order to visualize the separation of DNA fragments based on their size. Fluorescence could be visualized through UV transilluminator in presence of $\mathrm{EtBr}$ in the samples. In case of placenta extract a smear has been observed probably due to the different sized PDRN fragments present in the extract. Reasonable amount of fluorescence was detected in case of the DNA marker (Figure 1).

\subsection{Thin Layer Chromatography}

In TLC with silica gel, two solvent systems were selected where the $\mathrm{R}_{\mathrm{f}}$ of different spots of placenta extract and that of with EtBr varied between 0.4 and 0.9 and their migrations were compared and monitored at $366 \mathrm{~nm}$ and $254 \mathrm{~nm}(\mathrm{n}=3)$ (Table 1). In all sets, EtBr were included as control. A representative picture of TLC has been shown in Figure 2. In both the chromatograms (Figure 2. profile $1 \&$ profile 2) the components of the extract were distinctly separated. It was observed that a fraction of the extract binds with $\mathrm{EtBr}$ and during binding the spectral property of EtBr has also been changed (profile $1 \mathrm{C}$, Figure 2). The separated spots were detected for the placental extract in both the chromatograms (profile $1 \& 2$, B). Placental extract in addition to the nucleotides contain other components as well which had different $R_{\mathrm{f}}$ ranging from 0 to 1 in different solvent system (Table 1). Spots from placental extract had some trailing and were found to be diffused possibly due to salts and other accompanying materials.

\subsection{Reversed Phase HPLC (RP-HPLC)}

To confirm the identity of the component of the extract that binds with $\mathrm{EtBr}$ and distinctly separated in TLC (profile 1, B2, Figure 2), the spot was eluted from the TLC plate and subjected to reversed phase HPLC analysis. 


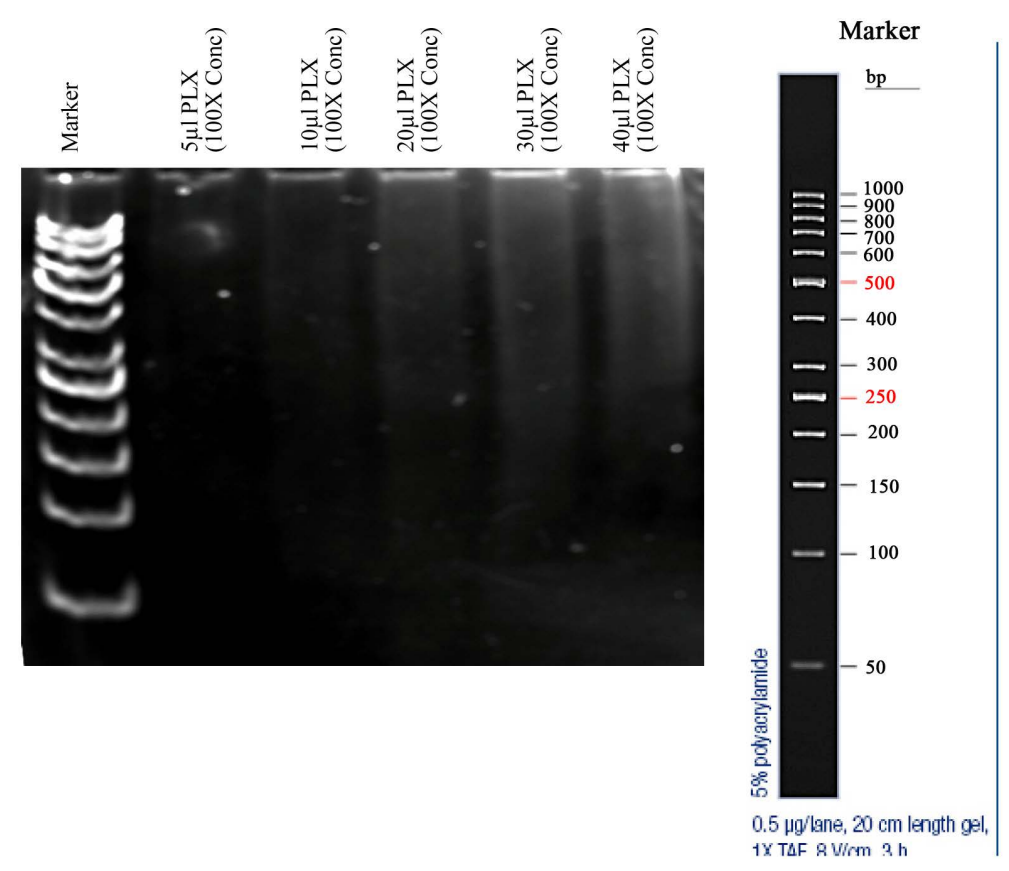

Figure 1. 15\% native PAGE of human placental extract in different concentration (with EtBr) showing smear of PDRNs.

Profile 1

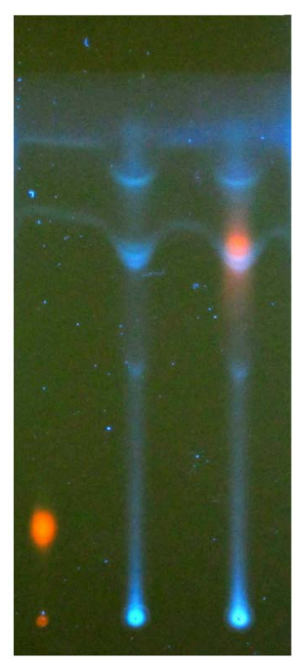

A B
Profile 2

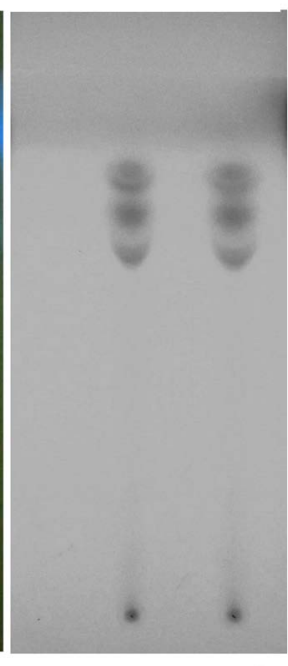

Figure 2. TLC profiles of Placenta extract, monitored at $366 \mathrm{~nm}$ (profile 1) and $254 \mathrm{~nm}$ (profile 2) respectively. The solvent system was Ethanol: methanol: ethyl acetate: water (50:30:10:10). Where, $A=36 \mathrm{ng}$ of $\mathrm{EtBr}, \mathrm{B}=5 \mu \mathrm{l}$ of $25 \times$ placenta extract and $\mathrm{C}=$ placenta extract with $\mathrm{EtBr}(5 \mu \mathrm{l}$ of $25 \times$ placenta extract containing 36ng of EtBr).

The RP-HPLC profile of the spot was monitored at 220 as well as $260 \mathrm{~nm}$ under defined conditions has been shown in Figure 3. It shows occurrence of two major (retention time $R \mathrm{t}=3.5 \pm 0.05$ and $4.9 \pm 0.05 \mathrm{~min}$ ) peaks at $220 \mathrm{~nm}$ and one major peak at $260 \mathrm{~nm}$ (retention time $R \mathrm{t}=3.5 \pm 0.05 \mathrm{~min})(\mathrm{n}=3)$. Retention of CT-DNA under identical conditions corresponded to the peak $R \mathrm{t}=3.5 \pm 0.05 \mathrm{~min}$ at $220 \mathrm{~nm}$ (Figure 3). The peak of the spot B2 (Figure 2) also corresponds to the peak of CT DNA when monitored at $260 \mathrm{~nm}$. It was observed that the elution profile of CT-DNA was different from the profile of B2 at $260 \mathrm{~nm}$. 
Table 1. Silica gel TLC profiles of Placentrex with or without ethidium bromide monitored at $366 \mathrm{~nm}$ (profile 1) and $254 \mathrm{~nm}$ (profile 2).

\begin{tabular}{|c|c|c|}
\hline \multirow{2}{*}{ Solvent system } & \multirow{2}{*}{$\begin{array}{c}\text { Profile } 1 \\
\mathbf{R}_{\mathbf{f}}\end{array}$} & \multirow{2}{*}{$\begin{array}{c}\text { Profile } 2 \\
\mathbf{R}_{\mathbf{f}}\end{array}$} \\
\hline & & \\
\hline \multirow{7}{*}{ Ethanol:acetic acid:water (80:10:10) } & \multirow{7}{*}{$\begin{array}{l}A=0.663 \\
C=0.717\end{array}$} & $A=0.662$ \\
\hline & & $\mathrm{B} 1=0.700$ \\
\hline & & $\mathrm{B} 2=0.811$ \\
\hline & & $\mathrm{B} 3=0.897$ \\
\hline & & $\mathrm{C} 1=0.717$ \\
\hline & & $\mathrm{C} 2=0.803$ \\
\hline & & $\mathrm{C} 3=0.914$ \\
\hline \multirow{7}{*}{$\begin{array}{l}\text { Ethanol:methanol:ethyl acetate:water } \\
\qquad(50: 30: 10: 10)\end{array}$} & $\mathrm{A}=0.177$ & $\mathrm{~A}=$ no spot was detected \\
\hline & $\mathrm{B} 1=0.439$ & $\mathrm{~B} 1=0.654$ \\
\hline & $\mathrm{B} 2=0.654$ & $\mathrm{~B} 2=0.744$ \\
\hline & $\mathrm{B} 3=0.808$ & $\mathrm{~B} 3=0.808$ \\
\hline & $\mathrm{C} 1=0.446$ & $\mathrm{C} 1=0.652$ \\
\hline & $\mathrm{C} 2=0.652$ & $\mathrm{C} 2=0.737$ \\
\hline & $\mathrm{C} 3=0.801$ & $\mathrm{C} 3=0.801$ \\
\hline
\end{tabular}

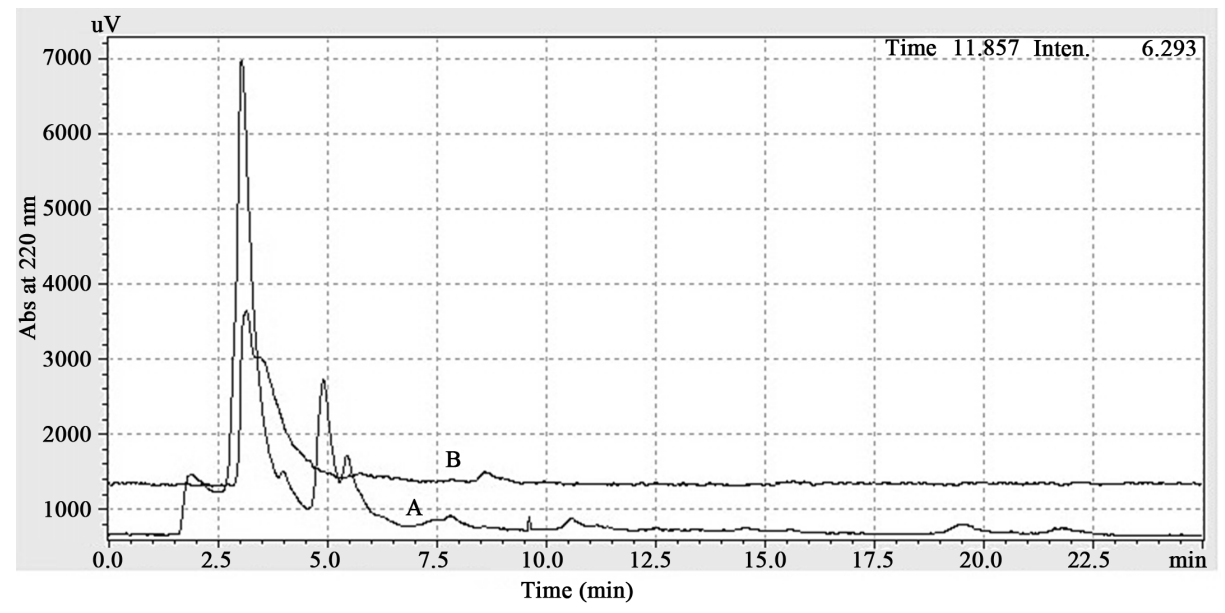

(A)

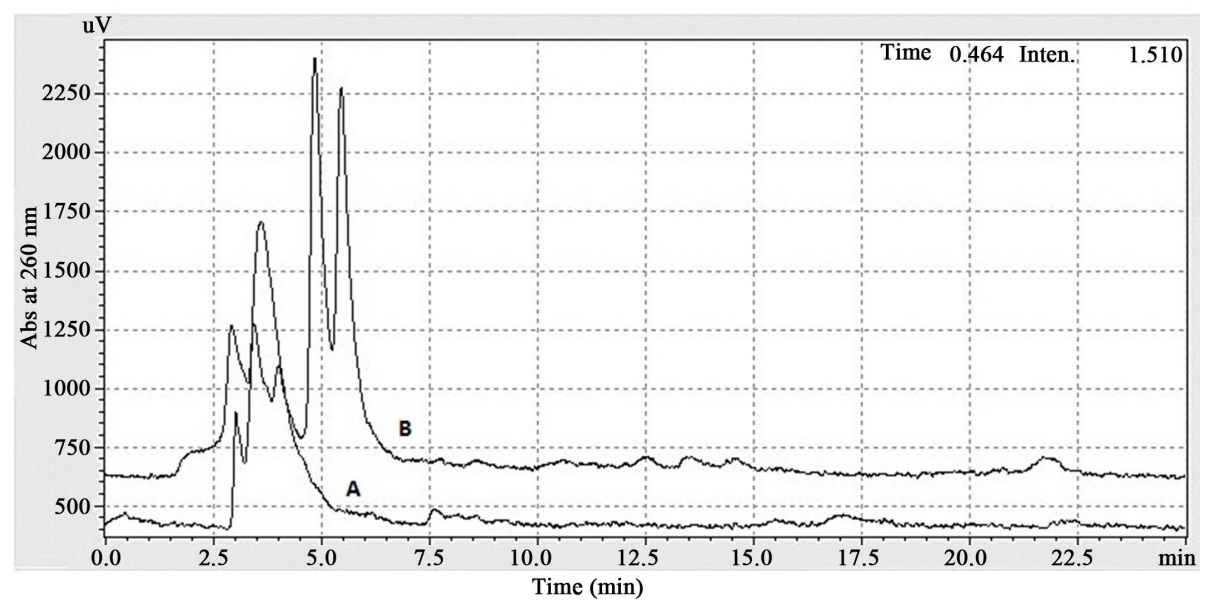

(B)

Figure 3. RP-HPLC profile of the eluted spot B2 from TLC plate, profile 1 (A), superimposed with standard CT-DNA (B) monitored at 220 as well as $260 \mathrm{~nm}$. 


\subsection{Spectrofluorimetric Analysis}

1) Preparation of standard curve by CT-DNA

CT-DNA working solution in water was prepared at a concentration of $0.2 \mathrm{mg} / \mathrm{ml}$. A calibration curve was constructed with 0.5 - $5 \mu \mathrm{g} / \mathrm{ml}$ of CT-DNA with a fixed concentration of EtBr $(0.29 \mu \mathrm{g} / \mathrm{ml})$ in Tris-EDTA buffer (pH 7.4) against fluorescence intensity (ex: $270 \mathrm{~nm}$; em max $_{1} 599 \mathrm{~nm}$; slit-widths ex/em: 10/5 nm) linear dependence was observed $\left(\mathrm{R}^{2}=0.992, \mathrm{R}^{2}=\right.$ regression coefficient). The points of the curve were the average of three sets where maximum variation observed was $\pm 3 \%$ (Figure 4 ).

2) Preparation of standard curve of Placental Extract

Different concentrations of placenta extract (5 - $35 \mu \mathrm{l} / \mathrm{ml})$ were taken in Tris-EDTA buffer (pH 7.4) with a fixed concentration of $\mathrm{EtBr}(0.29 \mu \mathrm{g} / \mathrm{ml})$ and were subjected to fluorescence analysis. Placenta extract demonstrated linear dependence of fluorescence intensity (ex: $270 \mathrm{~nm}$; em max $: 578.50 \mathrm{~nm}$; slit widths ex/em: 10/5 nm) with concentration under the experimental conditions $\left(\mathrm{R}^{2}=0.976\right)$. The points of the curve were the average of three sets where maximum variation observed was $\pm 3 \%$ (Figure 5 ).

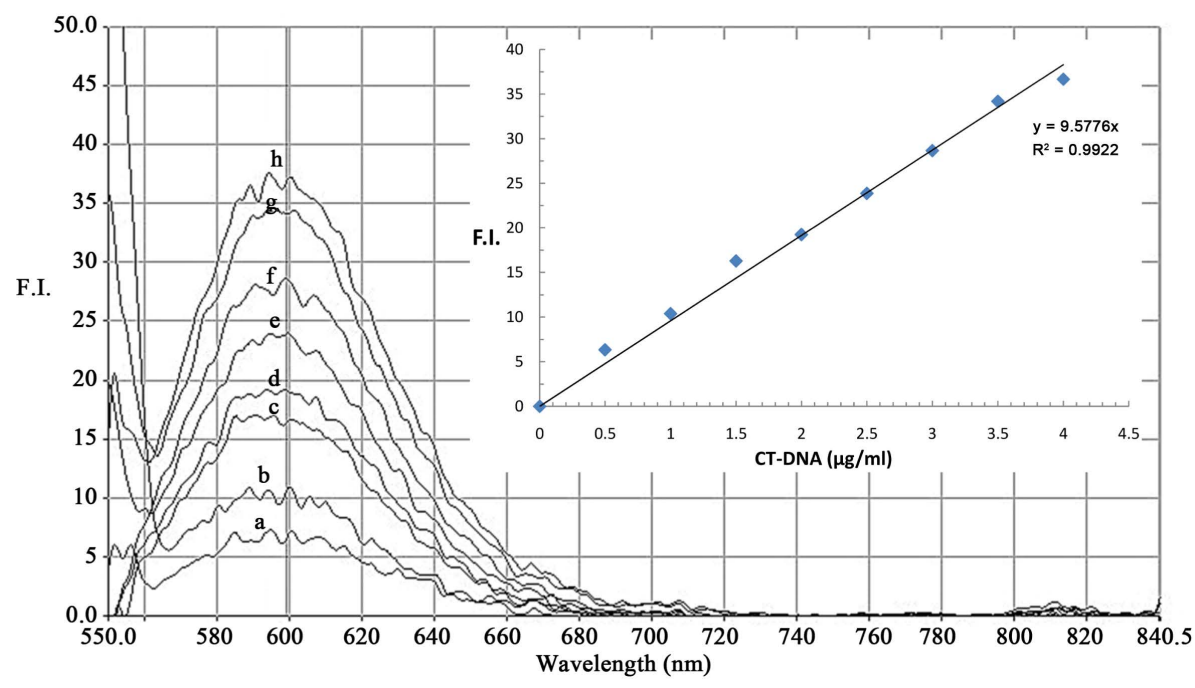

Figure 4. Standard Curve of CT-DNA (after binding with a fixed concentration of EtBr 0.29 $\mu \mathrm{g} / \mathrm{ml}$ ) (inset). The source data along with the spectra has been provided.

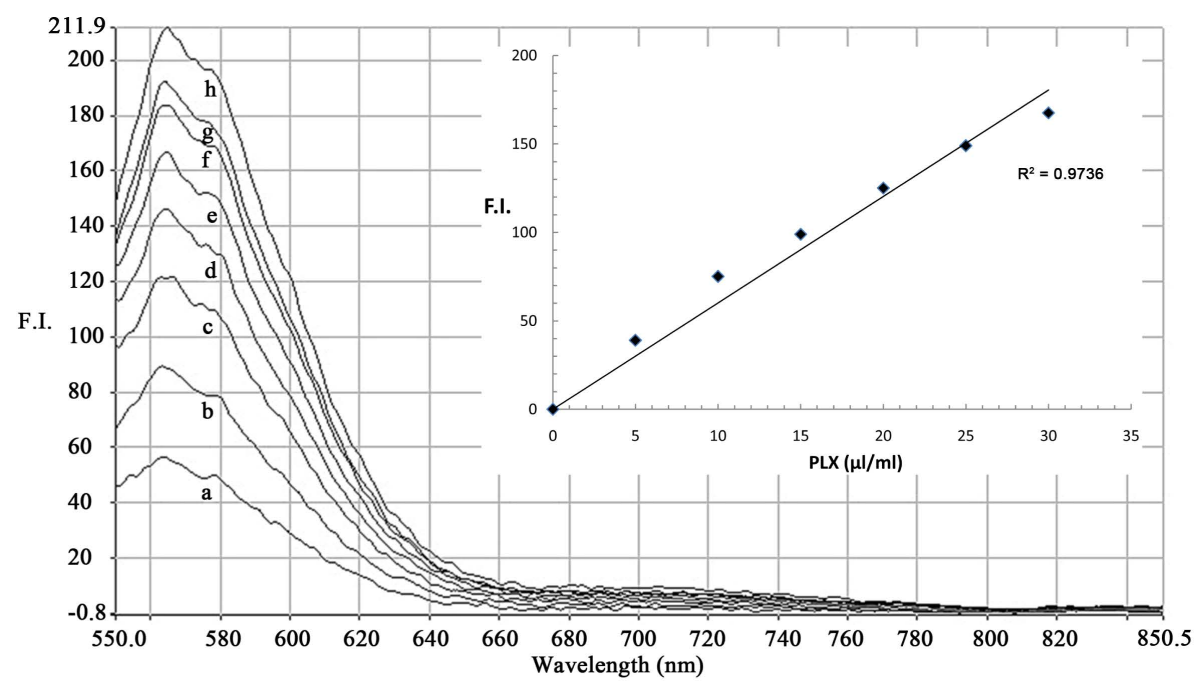

Figure 5. Linear dependence of increasing concentrations of placenta extract (after binding with a fixed concentration of EtBr i.e. $0.29 \mu \mathrm{g} / \mathrm{ml}$ ) with fluorescence Intensity (F.I.) at $\mathrm{Em}_{\max }$ i.e. $578.5 \mathrm{~nm}$ (inset). Source data along with spectra has been provided. 


\section{3) Determination of PDRN concentration}

The resultant spectra were obtained by subtracting the spectral value of the background emission spectrum of placental extract (ex: $270 \mathrm{~nm})$ marked as (a), from the spectrum of placenta extract with EtBr (ex: $270 \mathrm{~nm}$ ) marked as (a') (Figure 6 \& Figure 7). Concentrations of PDRNs in test samples i.e. human placenta extract of different batches $(n=100)$ were calculated from the standard curve of CT-DNA based on the intensity of resultant spectra (i.e. a'-a) at emission maxima (i.e. $617.0 \mathrm{~nm}$ ) (Figure 7). This spectral arithmetic was done by the data analysis tool of the inbuilt software FL-WinLab of the instrument. Furthermore, by increasing concentration of the extract (from $5 \mu \mathrm{l}-35 \mu \mathrm{l}$ ), with and without the fixed concentration of $\operatorname{EtBr}(0.29 \mu \mathrm{g} / \mathrm{ml}$ ), the difference in F.I. were obtained from the "resultant spectra" at two specific wavelength. It has been observed that at $564.5 \mathrm{~nm}$ the F.I. was increasing while at $617.0 \mathrm{~nm}$ was decreasing in nature. Both the increment as well as decrement of F.I. in "resultant spectra" shows linear dependence at the specified wavelength (Figure 8 \& Figure 9).

\subsection{Statistical Analysis}

The statistical analysis of the data has been done considering 2-sigma limit (Figure 10). One can use 3-sigma limit for quality control check as this is a standard one and contains $99.73 \%$ observations when the underlying variable follows a normal (Gaussian) distribution. The reason of taking 2-sigma here is to be stricter about quality

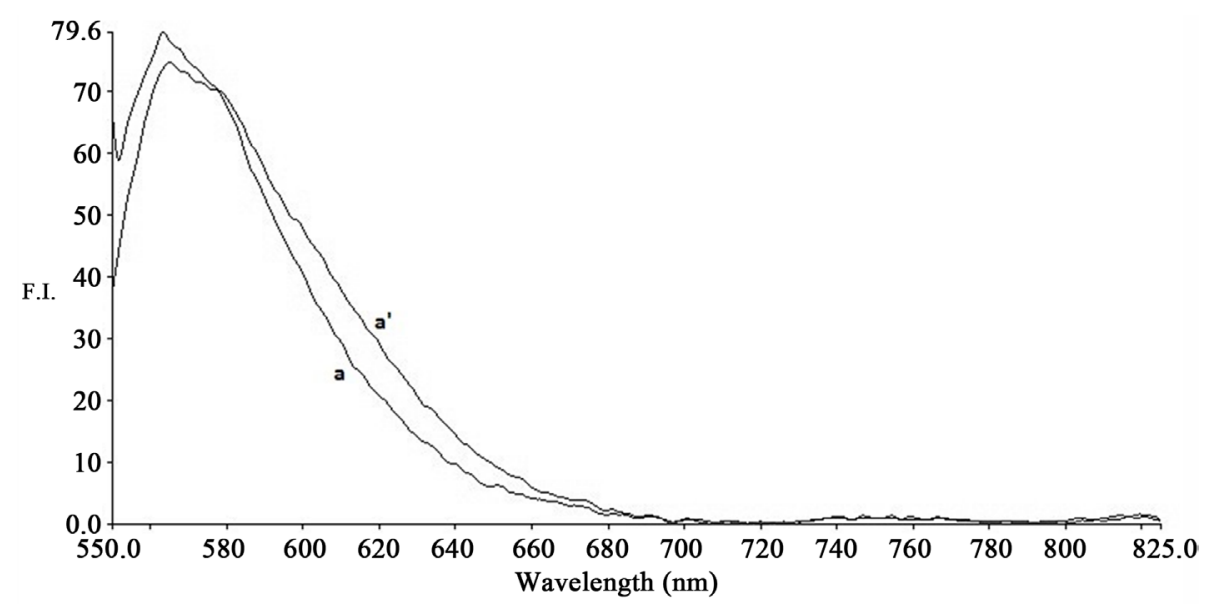

Figure 6. Emission spectra of placenta extract $2.5 \mu \mathrm{l}$ per ml of buffer (a); placenta extract 2.5 $\mu \mathrm{l}$ with EtBr of $0.29 \mu \mathrm{g} / \mathrm{ml}$ per $\mathrm{ml}$ of buffer (a') (Ex: $270 \mathrm{~nm})$.

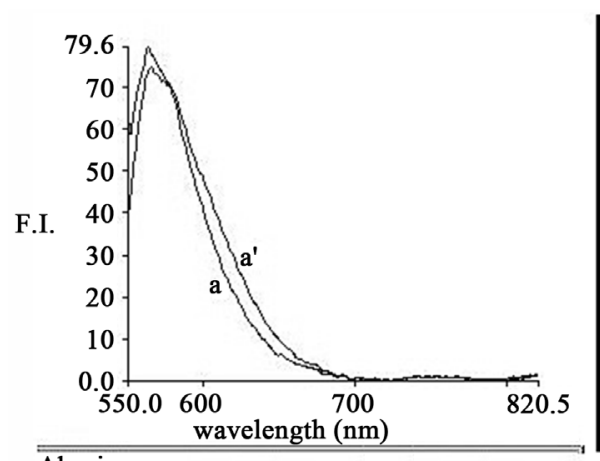

Abscissa

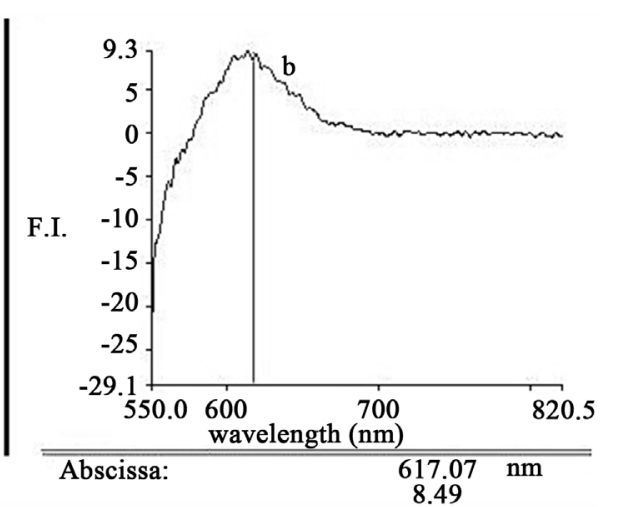

(B)

(A)

Figure 7. Subtraction of the background emission of placental extract (a) from the emission of placenta extract with $\mathrm{EtBr}$ (a') after excitation at $270 \mathrm{~nm}$ (i.e. a'-a). This is done by the data analysis tool of the inbuilt software FL-WinLab of the spectrofluorimeter (LS-55 PerkinElmer). 


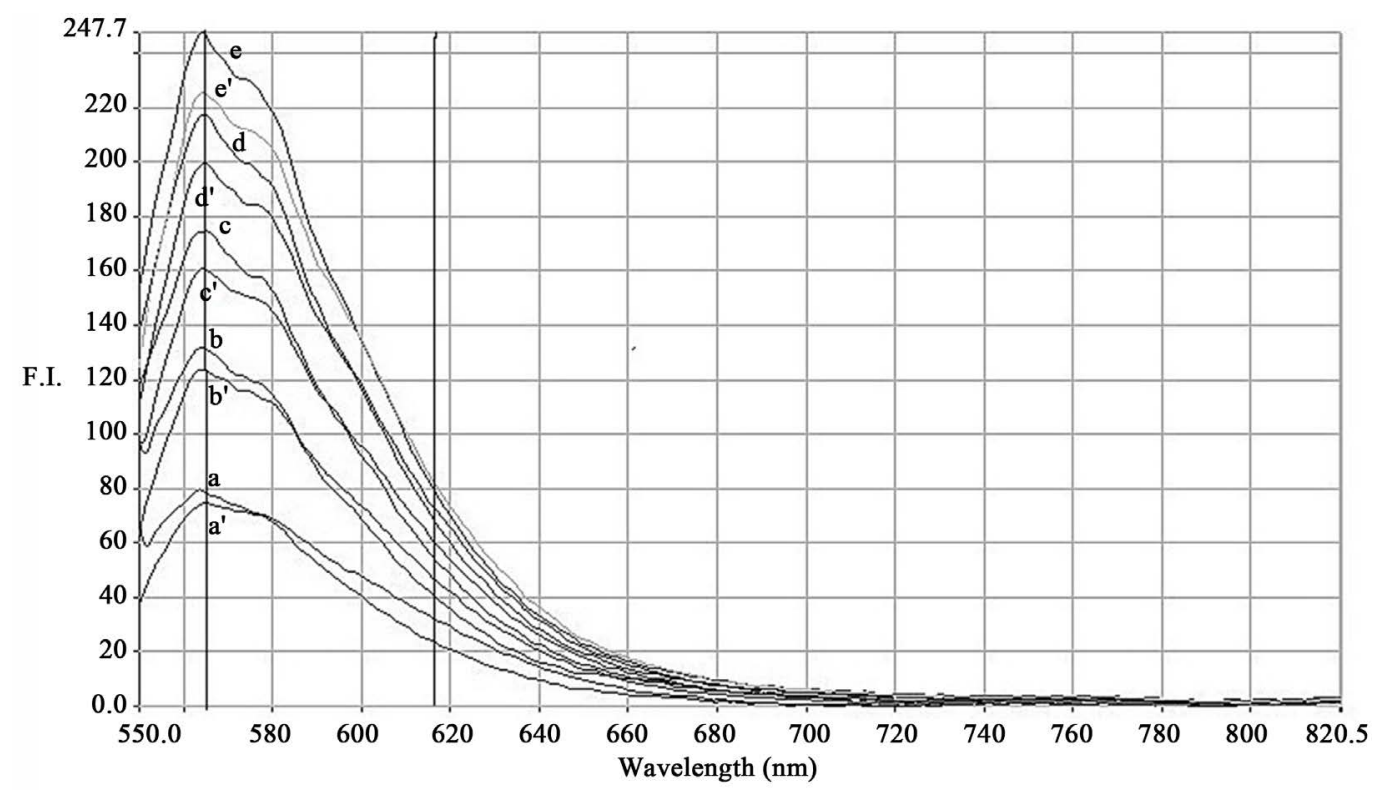

Figure 8. Emission spectra (Ex: $270 \mathrm{~nm}$ ) of increasing concentration of placenta extract (5 - $25 \mu \mathrm{l})$ with (a', b', c', d', e') and without (a, b, c, d, e) a fixed concentration $\operatorname{EtBr}(0.29 \mu \mathrm{g} / \mathrm{ml})$.

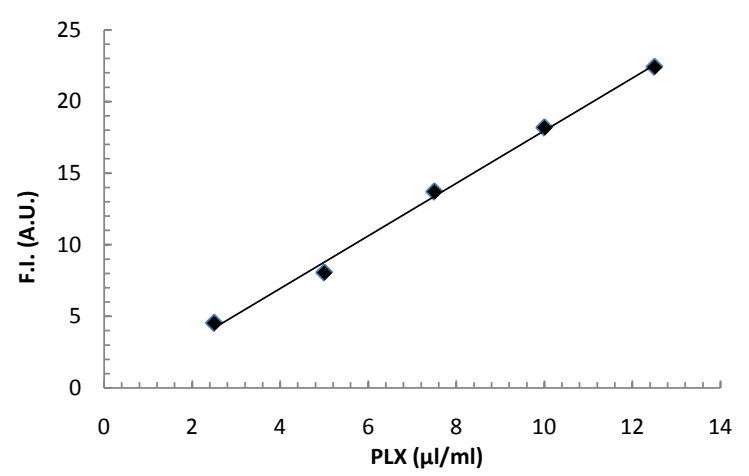

(A)

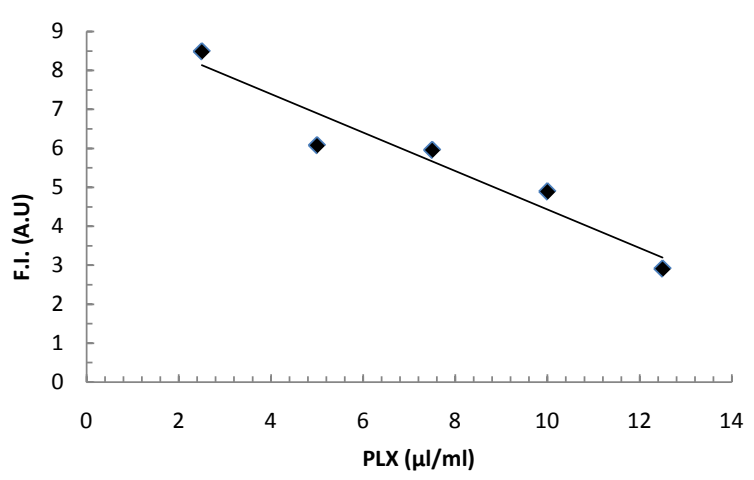

(B)

Figure 9. (A) = The difference between increasing concentrations of placenta extract binds with EtBr (fixed concentration) and placenta extract of the corresponding concentration (without EtBr) have resulted in increased in F.I. at 564.29 nm. F.I. of (a - a'), (b - b'), (c - c'), (d - d') and (e - e') of Figure 8 shows linear dependence with the concentration of placenta extract; $(\mathrm{B})$ = The difference between increasing concentrations of placenta extract binds with Etbr (fixed concentration) and placenta extract of the corresponding concentration (without EtBr) have resulted in decreased in F.I. at 617.07 nm. F.I. at $617.07 \mathrm{~nm}$ of (a' - a), (b’ - b), (c' - c), (d' - d) and (e' - e) of Figure 8 shows linear dependence with the concentration of placenta extract.

control. The observations beyond "blue" lines are taken as "not meeting standard”. The interpretation is same if we use the red lines. The entire calculation is done based on average values where in each subgroup the number of observations is 3 .

Using the above mentioned method 100 batches of placenta extract have been tested so far yielded the range of PDRN: Lower level = $158.30 \mu \mathrm{g} / \mathrm{ml}$; Upper level = $239.03 \mu \mathrm{g} / \mathrm{ml}$ and Mean level = $198.66 \mu \mathrm{g} / \mathrm{ml}$.

\section{Discussion}

PDRN has no such antigenic properties since it consists of low molecular weight DNA fragments, can be defined as deoxyribonucleotide linear polymers [23]. The ability of PDRN to promote wound healing was also confirmed by several studies [6]-[12]. An aqueous extract of human placenta used as wound healer is a rich source of bioactive peptides like fibronection type III, ubiquitin, some small molecules including PDRNs [13]-[17]. In 


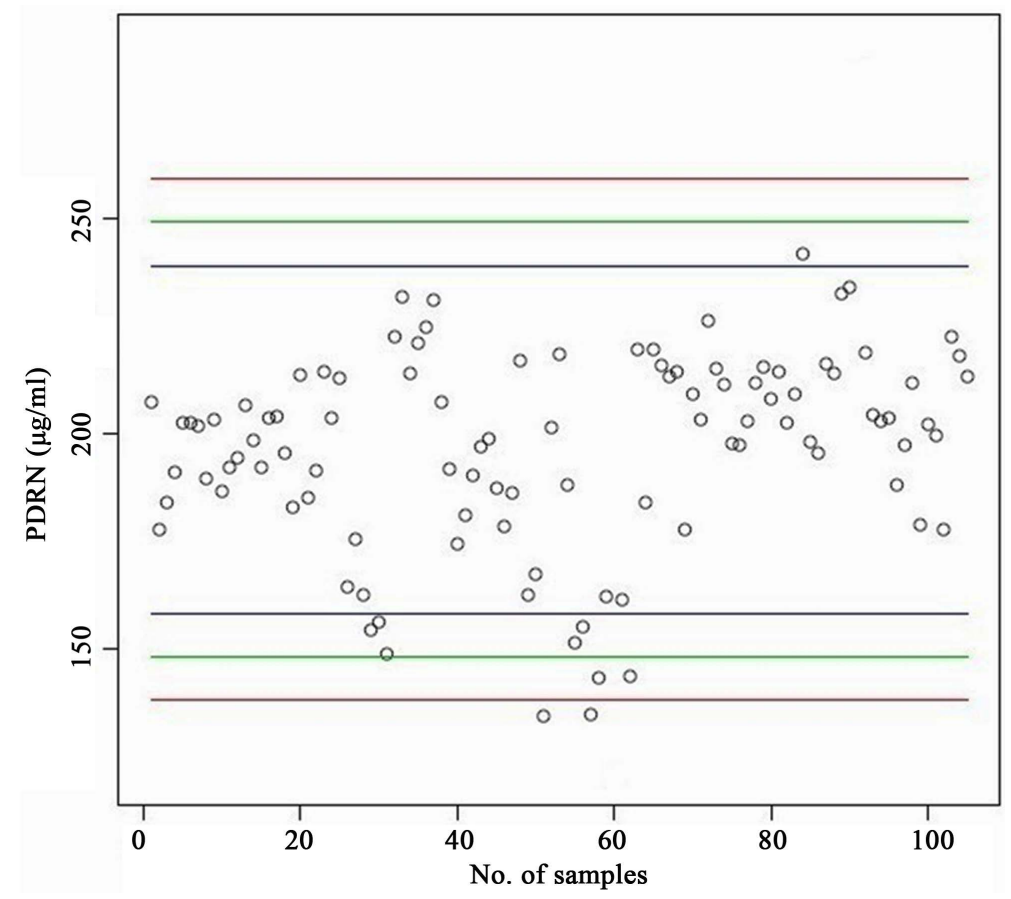

Figure 10. Normal distribution of PDRN concentration in different batches of placental extract $(n=100)$.

PAGE of the placenta extract viewed with EtBr, a smear has been observed probably due to the different sized PDRN fragments present in the extract (Figure 1). The same kind of profile of PDRNs in aqueous extract of human placenta had been shown earlier by Tonello et al. [3]. In PAGE, a fluorescence band was observed at the top which may be a fraction of PDRNs bound with peptide molecule/s present in the extract. This is likely to be happened in multi-component extract due to its manufacturing in relatively harsh condition with excess temperature and pressure.

Earlier quantitation of DNA has been demonstrated by spectrofluorimetry using EtBr since the fluorephore specifically binds with DNA [21]. PDRN is a mixture of small sized DNA fragments of different molecular weight, an attempt has been made whether the fluorimetric method by using external fluorephore $(\mathrm{EtBr})$ is workable for its estimation in such a multi-component biological extract. The fluorescence intensity was observed at $\mathrm{Em}_{\max }$ after excitation at $270 \mathrm{~nm}(\mathrm{Em}$ : $550-850 \mathrm{~nm})$. This was considered after ascertaining the fact that $\mathrm{EtBr}$ alone has no detectable fluorescence in the said spectral zone. But after binding with the specific component of the extract the spectral property of the $\mathrm{EtBr}$ has been changed which is distinctly observed also in TLC (profile 1. spot A and B) (Figure 2).

A concentration of $0.29 \mu \mathrm{g} / \mathrm{ml} \mathrm{EtBr}$ allowed to reach a detection limit of $0.5 \mu \mathrm{g} / \mathrm{ml}$ of standard CT-DNA, with a linear range from $0.5-5 \mu \mathrm{g} / \mathrm{ml}$ of buffer $\left(\mathrm{R}^{2}=0.992\right)$. The same concentration of $\mathrm{EtBr}$ exhibits a linear range of measurements of placenta extract from $5-35 \mu \mathrm{l} / \mathrm{ml}$ of buffer $\left(\mathrm{R}^{2}=0.976\right)$. The points of the curve were the average of three sets where maximum variation observed was $\pm 3 \%$. During fluorescence analysis the shift of $\mathrm{em}_{\max }$ about $20 \pm 2 \mathrm{~nm}$ from standard CT-DNA has been found for placenta extract. It could be considered as the binding of EtBr with the DNA fragments present in the multi-component extract. This binding was further confirmed by TLC analysis by observing distinct separated spot of placenta extract bound with EtBr (profile 1, B2). Earlier spectral shift in placenta extract has also been observed in case of NADPH quantitation [13]. The spectral shift is a common phenomenon for the binding of fluorephore in with the specific molecules in a multi-component system [13] [14]. It has been observed that the extract without addition of EtBr has some background fluorescence in the said spectral zone. For obtaining "resultant spectra" background fluorescence correction was done for the proper estimation of PDRNs (Figure 7). Moreover, by increasing concentration of the extract with and without the fixed concentration of $\mathrm{EtBr}$ the differences in F.I. were obtained from the 'resultant spectra'. It has been observed that at $564.5 \mathrm{~nm}$ the F.I. was increasing while at $617.0 \mathrm{~nm}$ was decreasing in nature (Figure 8 and Figure 9). This observation also indicates the binding of $\mathrm{EtBr}$ with the specific component of 
placenta extract.

TLC of placenta extract shows separation of components of placenta extract (Figure 2, profile 1 \& 2) as well as binding of EtBr with the specific component of the extract (Figure 2, Profile 1(C)). An attempt has been made to confirm the component that binds with $\mathrm{EtBr}$ was deoxyribonuleotides. The separated spot was eluted from TLC plate by using standard protocol (described in 2.5) and subjected to RP-HPLC analysis. HPLC demonstrates that the peak of the eluted fraction of the extract corresponds to the standard CT-DNA when monitored at 220 as well as $260 \mathrm{~nm}$. The retention time of the major peak of both the sample and standard were identical when monitored at $220 \mathrm{~nm}$ (Figure 3). But it has also been found that the profile CT-DNA was a bit different from the profile of spot B2 when monitored at $260 \mathrm{~nm}$. This is most likely because placenta extract contains mixture of deoxyribonuleotides (i.e. PDRNs) and the difference is obvious at $260 \mathrm{~nm}$ when compared with the standard CT-DNA (Figure 3).

\section{Conclusion}

We have developed the method for estimation of PDRNs in aqueous extract of human placenta by fluorescence spectroscopy for the first time and it is successfully implemented for the analysis of different batches of placenta extract $(n=100)$. Earlier the batch wise consistency of different components of the indigenous aqueous extract of human placenta had been reported [24]. Here, the estimation of PDRN of different batches of placenta extract is also found to be significant by statistical analysis and the lower and upper levels are $158.30 \mathrm{and} 239.03 \mu \mathrm{g} / \mathrm{ml}$ respectively. In summary, consistent presence of PDRN in the extract has been demonstrated by the spectroflurimetric method. Since the role of PDRNs in anti-inflammatory action as well as tissue repair through varied mechanisms are well known [6]-[12], it is likely to act as an active components in the extract analyzed. Moreover, this easy-to-use method will help in quantitation of PDRNs for other biological extracts.

\section{Acknowledgements}

We are thankful to Dr. D.P. Ghosh, Dr. G.P. Srivastava and Dr S. Bandyopadhyay of Albert David Ltd., Kolkata for their technical suggestions. Our special thanks to Mr. Mainak Bose, Senior Research Fellow, CSIR-IICB, Kolkata, for helping in electrophoresis.

\section{References}

[1] Ramakrishnan, K.M. and Jayaraman, V. (1997) Management of Partial-Thickness Burn Wounds by Amniotic Membrane: A Cost-Effective Treatment in Developing Countries. Burns, 23, S33-S36. http://dx.doi.org/10.1016/S0305-4179(97)90099-1

[2] Chakraborty, P.D. and Bhattacharyya, D. (2012) Aqueous Extract of Human Placenta as a Therapeutic Agent in Recent Advances in Research on the Human Placenta. In Tech Publishers, Rijeka, 77-92. http://cdn.intechopen.com/pdfs-wm/31273.pdf

[3] Tonello, G., Daglio, M., Zaccarelli, N., Sottofattori, E., Mazzei, M. and Balbi, A. (1996) Characterization and Quantitation of the Active Polynucleotide Fraction (PDRN) from Human Placenta, a Tissue Repair-Stimulating Agent. Journal of Pharmaceutical and Biomedical Analysis, 14, 1555-1560. http://dx.doi.org/10.1016/0731-7085(96)01788-8

[4] Chakraborty, P.D. and Bhattacharyya, D. (2005) Isolation of Fibronectin Type III Like Peptide from Human Placental Extract Used as Wound Healer. Journal of Chromatography B, 818, 67-73. http://dx.doi.org/10.1016/j.jchromb.2004.09.059

[5] Biswas, T.K., Auddy, B., Bhattacharyya, N.P., Bhattacharyya, S. and Mukherjee, B. (2001) Wound Healing Activity of Human Placental Extract in Rats. Acta Pharmacologica Sinica, 22, 1113-1116.

[6] Altavilla, D., Bitto, A., Polito, F., Marini, H., Minutoli, L., Di Stefano, V., Irrera, N., Cattarini, G. and Squadrito, F. (2009) Polydeoxyribonucleotide (PDRN): A Safe Approach to Induce Therapeutic Angiogenesis in Peripheral Artery Occlusive Disease and in Diabetic Foot Ulcers. Cardiovascular Hematological Agents in Medicinal Chemistry, 7, 313321. http://dx.doi.org/10.2174/187152509789541909

[7] Sini, P., Denti, A., Cattarini, G., Daglio, M., Tira, M.E. and Balduini, C. (1999) Effect of Polydeoxyribonucleotides on Human Fibroblasts in Primary Culture. Cell Biochemistry and Function, 17, 107-114. http://dx.doi.org/10.1002/(SICI)1099-0844(199906)17:2<107::AID-CBF815>3.0.CO;2-\#

[8] Guizzardi, S., Galli, C., Govoni, P., Boratto, R., Cattarini, G., Martini, D., Belletti, S. and Scandroglio, R. (2003) Polydeoxyribonucleotide (PDRN) Promotes Human Osteoblast Proliferation: A New Proposal for Bone Tissue Repair. 
Life Sciences, 73, 1973-1983. http://dx.doi.org/10.1016/S0024-3205(03)00547-2

[9] Rubegni, P., De Aloe, G., Mazzatenta, C., Cattarini, L. and Fimiani M. (2001) Clinical Evaluation of the Trophic Effect of Polydeoxyribonucleotide (PDRN) in Patients Undergoing Skin Explants. A Pilot Study. Current Medical Research and Opinion, 17, 128-131. http://dx.doi.org/10.1185/0300799039117047

[10] Thellung, S., Florio, T., Maragliano, A., Cattarini, G. and Schettini, G. (1999) Polydeoxyribonucleotides Enhance the Proliferation of Human Skin Fibroblasts: Involvement of A2 Purinergic Receptor Subtypes. Life Sciences, 64, 16611674. http://dx.doi.org/10.1016/S0024-3205(99)00104-6

[11] Valdatta, L., Thione, A., Mortasino, C., Buoro, M. and Tuinder, S. (2004) Evaluation of the Efficacy of Polydeoxyribonucleotides in the Healing Process of Autologous Skin Graft Donor Sites: A Pilot Study. Current Medical Research and Opinion, 20, 403-404. http://dx.doi.org/10.1185/030079904125003116

[12] Lazzarotto, M., Tomasello, E.M. and Caporossi, A. (2004) Clinical Evaluation of Corneal Epithelialization after Photorefractive Keratectomy in Patients Treated with Polydeoxyribonucleitide (PDRN) Eye Drops: A Randomized, Double-Blind, Placebo-Controlled Trial. European Journal of Ophthalmology, 14, 284-289.

[13] Datta, P. and Bhattacharyya, D. (2004) Spectroscopic and Chromatographic Evidences of NADPH in Human Placental Extract Used as Wound Healer. Journal of Pharmaceutical and Biomedical Analysis, 34, 1091-1098. http://dx.doi.org/10.1016/S0731-7085(03)00654-X

[14] De, D., Chakraborty, P.D. and Bhattacharyya, D. (2009) Analysis of Free and Bound NADPH in Aqueous Extract of Human Placenta Used as Wound Healer. Journal of Chromatography B, 877, 2435-2442. http://dx.doi.org/10.1016/j.jchromb.2009.05.018

[15] De, D., Chakraborty, P.D. and Bhattacharyya, D. (2010) Regulation of Trypsin Activity by Peptide Fraction of an Aqueous Extract of Human Placenta Used as Wound Healer. Journal of Cellular Physiology, 226, 2033-2040. http://dx.doi.org/10.1002/jcp.22535

[16] De, D., Chakraborty, P.D., Mitra, J., Sharma, K., Mandal, S., Das, A., Chakrabarti, S. and Bhattacharyya, D. (2013) Ubiquitin-Like Protein from Human Placental Extract Exhibits Collagenase Activity. PLoS ONE, 8, e59585. http://dx.doi.org/10.1371/journal.pone.0059585

[17] Chakraborty, P.D. and Bhattacharyya, D. (2005) In Vitro Growth Inhibition of Microbes by Human Placental Extract. Current Science, 88, 782-786.

[18] Chakraborty, P.D., Bhattacharyya, D., Pal, S. and Ali, N. (2006) In Vitro Induction of Nitric Oxide by Mouse Peritoneal Macrophages Treated with Human Placental Extract. International Immunopharmacology, 6, 100-107. http://dx.doi.org/10.1016/j.intimp.2005.07.018

[19] Nath, S., Bhattacharyya, D. (2007) Cell Adhesion by Aqueous Extract of Human Placenta Used as Wound Healer. Indian Journal of Experimental Biology, 45, 732-738.

[20] Bonasera, V., Alberti, S. and Sacchetti, A. (2007) Protocol for High-Sensitivity/Long Linear-Range Spectrofluorimetric DNA Quantification Using Ethidium Bromide. BioTechniques, 43, 173-176. http://dx.doi.org/10.2144/000112500

[21] Tataurov, A.V., You, Y. and Owczarzy, R. (2008) Predicting Ultraviolet Spectrum of Single Stranded and Double Stranded Deoxyribonucleic Acids. Biophysical Chemistry, 133, 66-70. http://dx.doi.org/10.1016/j.bpc.2007.12.004

[22] Glasel, J. (1995) Validity of Nucleic Acid Purities Monitored by 260/280 Absorbance Ratios. BioTechniques, 18, 6263.

[23] Bitto, A., Polito, F., Altavilla, D., Minutoli, L., Migliorato, A. and Squadrito, F. (2008) Polydeoxyribonucleotide (PDRN) Restores Blood Flow in an Experimental Model of Peripheral Artery. Journal of Vascular Surgery, 48, 12921300. http://dx.doi.org/10.1016/j.jvs.2008.06.041

[24] Datta, P. and Bhattacharyya, D. (2004) Analysis of Fluorescence Excitation-Emission Matrix of Multicomponent Drugs. A Case Study with Human Placental Extract Used as Wound Healer. Journal of Pharmaceutical and Biomedical Analysis, 36, 211-218. http://dx.doi.org/10.1016/j.jpba.2004.05.006 
Scientific Research Publishing (SCIRP) is one of the largest Open Access journal publishers. It is currently publishing more than 200 open access, online, peer-reviewed journals covering a wide range of academic disciplines. SCIRP serves the worldwide academic communities and contributes to the progress and application of science with its publication.

Other selected journals from SCIRP are listed as below. Submit your manuscript to us via either submit@scirp.org or Online Submission Portal.
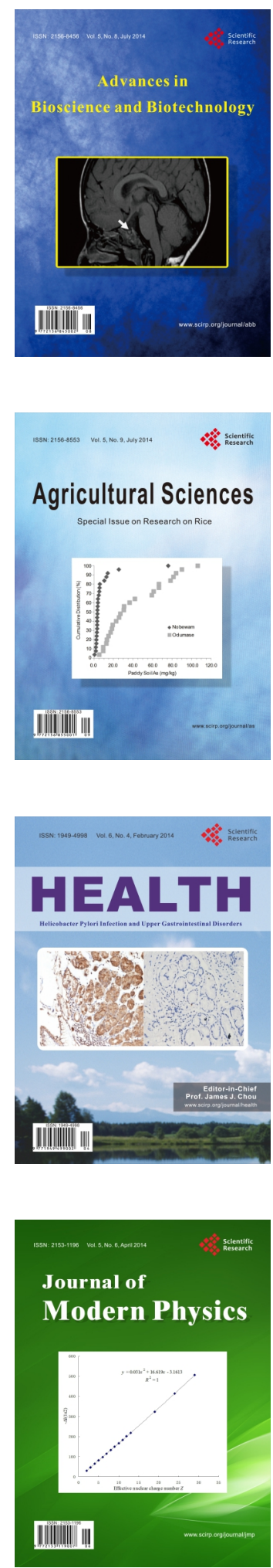
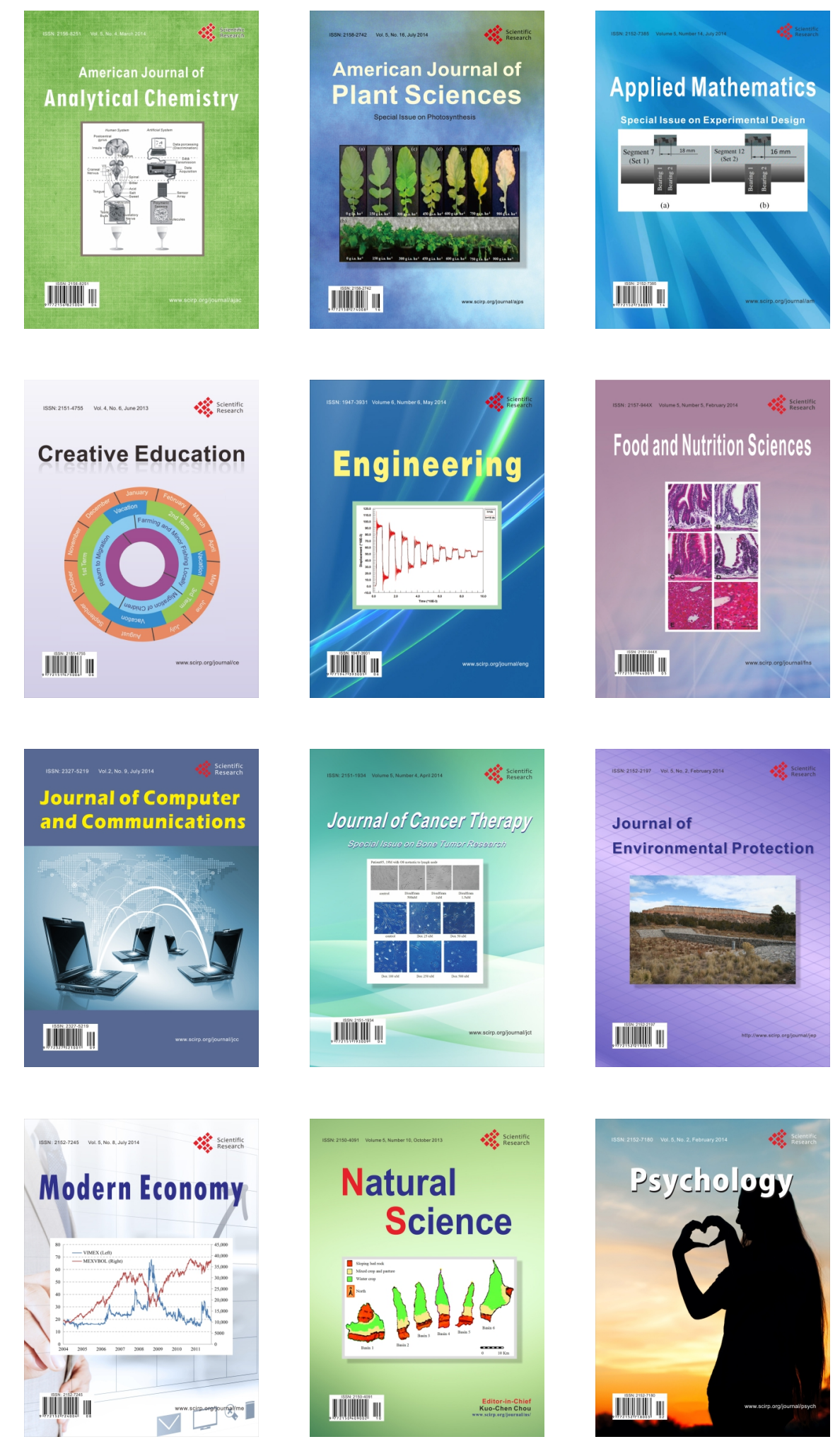